\title{
Long term follow up of multifocal motor neuropathy with conduction block under treatment
}

\author{
J-Ph Azulay, P Rihet, J Pouget, F Cador, O Blin, J Boucraut, G Serratrice
}

\begin{abstract}
Eighteen patients (15 men, three women; age range 30 to 71 years, mean 45.8 years) with multifocal motor neuropathy treated with high dose intravenous immunoglobulin (IVIg) were evaluated for nine to 48 months (mean follow up $25 \cdot 3$ months). The median time between onset of multifocal motor neuropathy and treatment was 5.8 years. The dose of IVIg was $0.4 \mathrm{~g} / \mathrm{day}$ for three to five days. The interval between each treatment was determined for each patient by the evaluation of the effect of the first course. Muscle strength was evaluated by a computerised analyser. Clinical improvement was seen in 12 patients treated with IVIg (67\%). Isometric strength increased from $32 \%$ to 97\% (mean $54.5 \%$ ) of the initial value. Functional scales corroborated these findings. No clear predictive factors of response to IVIg was found except the presence of high titres of IgM anti-GM1 antibodies. Often, patients needed repeated courses of IVIg to maintain the improvement. In two patients, IVIg infusions were stopped without signs of relapse after one year. Four patients were initially treated with prednisone ( $1 \mathrm{mg} / \mathrm{kg} /$ day), without any clear improvement. Five patients with no response to IVIg or who were IVIg dependent were treated with cyclophosphamide, but only one showed improvement. These results show the long term benefits and safety of IVIg in multifocal motor neuropathy but also the transient effect of this expensive treatment in most patients.
\end{abstract}

(F Neurol Neurosurg Psychiatry 1997;62:391-394)

Keywords: multifocal motor neuropathy; intravenous immunoglobulin; anti-GM1 antibodies

Lewis et al in $1982^{1}$ reported the first description of a chronic, asymmetric sensorimotor neuropathy predominantly affecting the upper limbs, characterised by a pattern of multifocal, segmental demyelination. Two patients out of five improved with corticosteroids whereas three untreated patients showed little deterioration. Further reports emphasised the absence of sensory involvement, suggesting that it was a new lower motor neuron disease. ${ }^{23}$ Initial therapeutic trials with prednisone or plasma exchange were unsuccessful. ${ }^{34}$ The first reports of drug induced improvement in the so-called multifocal motor neuropathy was with cyclophosphamide $^{5-7}$ The potentially serious side effects of long term immunosuppressive treatment encourages the use of safer drugs such as intravenous immunoglobulins (IVIg). Recently, the effectiveness of IVIg in multifocal motor neuropathy was shown in multiple trials, ${ }^{8} 18$ two of them being performed with placebo controls. ${ }^{13-17}$ However, IVIg is an expensive treatment with a short duration of action, and most studies have only assessed its effects in the short term. The usefulness of IVIg long term has yet to be shown. To evaluate the benefit of IVIg over periods longer than 12 months, we reviewed all the patients with multifocal motor neuropathy treated in our department over the past four years.

\section{Patients and methods}

Over the past four years, 18 patients diagnosed as having multifocal motor neuropathy (14 men and four women) have been treated in the neuromuscular clinic at La Timone Hospital. The diagnosis was based on the presence of a chronic, progressive, asymmetric neuropathy predominantly affecting the upper limbs with or without mild sensory loss and electrophysiological evidence of motor conduction block.

Anti-Gml antibody titres were measured before each infusion by a modified version of the standard enzyme linked immunosorbent assay (ELISA) protocol. ${ }^{16}$ The titres were controlled before each infusion and tests for HIV and hepatitis B and C were carried out.

\section{ASSESSMENT OF TREATMENT RESPONSE AND}

CRITERIA FOR IMPROVEMENT

Clinical response was assessed before each infusion by evaluating the maximum voluntary isometric contraction (MVIC) with a computerised analyser (Myocomp, Meditronic instrument), and by a modified Rankin disability score. ${ }^{9}$ The MVIC score was obtained for eight muscles and always included the most affected muscles in the upper and lower limbs during a maximal isometric contraction lasting $10 \mathrm{sec}-$ onds. The measurement was always performed 
by the same examiner before drug treatment, with the patient in standard positions defined for each muscle tested. The eight muscle scores were summed to obtain a total MVIC score. The changes in muscle strength were expressed as a percentage of the baseline value obtained before starting the treatment. Patients were considered as responders if an increase $>30 \%$ of the initial strength (total score) was obtained at the end of the study. After the first treatment with IVIg, the score was also obtained at two, four, and eight week intervals to determine the optimal frequency of IVIg infusions needed to avoid deterioration. All patients received IVIg (Laboratoire Français du Fractionnement et des Biotechnologies) at a dose of $0.4 \mathrm{~g} / \mathrm{kg} /$ day, for three to five consecutive days at intervals determined for each patient after the first evaluation. A mean of 6.3 (range 2 to 15 ) infusions were performed per patient during a period of nine to 48 months with a mean follow up of 25.3 months. Four patients had been treated previously with steroids without any improvement.

\section{Results \\ PATIENTS}

The table shows the details of the 18 patients, 14 men and four women, ranging in age from 30 to 71 (mean $45 \cdot 8$ ) years who were evaluated. The median time between onset and treatment was 5.8 years. Symptoms started in the upper limbs in 17 patients. At the time of treatment all had an asymmetric limb weakness affecting only the upper limbs in eight patients and all four limbs in 10. All patients were ambulatory. The Rankin disability scale score before treatment was 2 or 3 in all. All patients were tested for IgM anti-GM1 antibody and 12 had raised titres ranging from 40 to 320 (mean 193.3). Motor nerve conduction studies showed evidence of motor conduction blocks in at least two motor nerves in all patients.

\section{RESPONSE TO TREATMENT}

Treatment with IVIg induced a final strength increase of at least $30 \%$ in 12 patients $(67 \%)$. The gain ranged from $32 \%$ to a near twofold increase of the initial measurement $(97 \%)$ with a mean of $54 \%$. Improvement by at least one grade on the Rankin scale paralleled these objective findings. Limited duration of action, requiring repeated courses, occurred in eight patients. The mean duration of effect of a course was 53 days. The maximal effect was always reached before the third infusion and was further maintained by repeated infusions. A mean of 6.3 infusions was performed per patient in this subgroup, followed by comparable responses in all except patient 3 who deteriorated after an initial improvement of $40 \%$, obtained with three courses of IVIg at eightweek intervals. The deterioration was not stopped by cyclophosphamide $(1.5 \mathrm{mg} / \mathrm{kg} /$ day $)$ for six months in association with monthly IVIg infusions $(0.4 \mathrm{~g} / \mathrm{kg} /$ day for three days).

A cumulative effect was seen after each course in four patients and the withdrawal of IVIg was possible for two of them (patients 1 and 9) without relapse after one year.

Treatment with IVIg was ineffective for six patients after three to seven courses. Three patients received intravenous cyclophosphamide treatment $\left(1 \mathrm{~g} / \mathrm{m}^{2}\right)$ every month (patients 2, 4, and 11). In all cases it was necessary to reduce the dose because of the presence of a leukopenia after two or three months; only one patient (2) improved after six months of treatment. In two patients (patients 3 and 17) oral cyclophosphamide $(1-1.5 \mathrm{mg} / \mathrm{kg})$ was added to IVIg; it enabled a delay in the frequency of IVIg infusions in one patient (17)

Eight patients experienced minor side effects during IVIg treatment, such as headache, fever, or rash. An aseptic meningitis occurred in one patient. Serological status for HIV and hepatitis $B$ and $C$ did not change during the course of the study.

Eleven of the 12 patients with a significant

Clinical and biological data and treatment responses of 18 patients

\begin{tabular}{|c|c|c|c|c|c|c|c|c|c|}
\hline $\begin{array}{l}\text { Sex and } \\
\text { patient no }\end{array}$ & $\begin{array}{l}\text { Age of } \\
\text { onset }(y)\end{array}$ & $\begin{array}{l}\text { Follow up } \\
\text { (months) }\end{array}$ & Weakness & Fasciculations & Amyotrophy & $D T R$ & $\begin{array}{l}\text { IgM anti- } \\
\text { GM1 titres }\end{array}$ & $\begin{array}{l}\text { CSF } \\
\text { protein (g/l) }\end{array}$ & $\begin{array}{l}\text { Treatment } \\
\text { response (\%) }\end{array}$ \\
\hline $\begin{array}{l}\text { M1 } \\
\text { M2 }\end{array}$ & $\begin{array}{l}31 \\
37\end{array}$ & $\begin{array}{l}18 \\
32\end{array}$ & $\begin{array}{l}\text { LUL } \\
4 \mathrm{~L}\end{array}$ & $\begin{array}{l}0 \\
+\end{array}$ & $\begin{array}{l}0 \\
+\end{array}$ & $\begin{array}{l}\mathrm{N} \\
0\end{array}$ & $\begin{array}{l}80 \\
40\end{array}$ & $\begin{array}{l}\text { ND } \\
0.67\end{array}$ & \multirow{6}{*}{$\begin{array}{l}\text { IVIg: +45 } \\
\text { IVIg: +0.5 } \\
\text { IVCTX: +30 } \\
\text { IVIg: +40/-12 } \\
\text { +Oral CTX: }-38 \\
\text { IVIg: +8 } \\
\text { IVCTX: +10 } \\
\text { IVIg: +3 } \\
\text { IVIg: + +36 } \\
\text { IVIg: }-59 \\
\text { IVIg: +97 } \\
\text { IVIg: +62 } \\
\text { IVIg: +16 } \\
\text { IVIg: }-28 \\
\text { IVCTX: }-24 \\
\text { IVIg: +32 } \\
\text { IVIg: +64 } \\
\text { IVIg: +63 } \\
\text { IVIg: +33 } \\
\text { IVIg: +45 } \\
\text { IVIg: + } 64 \\
\text { +Oral CTX: +8 } \\
\text { IVIg: + + }\end{array}$} \\
\hline M3 & 63 & 12 & $4 \mathrm{~L}$ & + & + & $\mathbf{N}$ & 160 & 0.40 & \\
\hline M4 & 30 & 48 & UL & + & + & 0 & 0 & 0.63 & \\
\hline $\begin{array}{l}\text { F5 } \\
\text { M6 } \\
\text { M7 } \\
\text { M8 } \\
\text { M9 } \\
\text { M10 } \\
\text { M11 }\end{array}$ & $\begin{array}{l}36 \\
47 \\
37 \\
29 \\
51 \\
59 \\
67\end{array}$ & $\begin{array}{r}18 \\
32 \\
18 \\
9 \\
18 \\
12 \\
12\end{array}$ & $\begin{array}{l}\text { LUL, RLL } \\
\text { RUL, LL } \\
\text { UL } \\
\text { 4L } \\
\text { RUL } \\
\text { UL } \\
\text { 4L }\end{array}$ & $\begin{array}{l}0 \\
+ \\
+ \\
+ \\
0 \\
+ \\
+\end{array}$ & $\begin{array}{l}+ \\
+ \\
+ \\
+ \\
0 \\
+ \\
+\end{array}$ & $\begin{array}{l}\mathbf{D} \\
\mathbf{N} \\
\mathbf{D} \\
\mathbf{N} \\
\mathbf{N} \\
\mathbf{N} \\
\mathbf{N}\end{array}$ & $\begin{array}{r}0 \\
320 \\
0 \\
160 \\
40 \\
0 \\
0\end{array}$ & $\begin{array}{l}0.50 \\
0.25 \\
0.68 \\
\text { ND } \\
0.30 \\
0.35 \\
0.57\end{array}$ & \\
\hline $\begin{array}{l}\text { M12 } \\
\text { M13 } \\
\text { F14 } \\
\text { F15 } \\
\text { M16 } \\
\text { M17 }\end{array}$ & $\begin{array}{l}26 \\
31 \\
29 \\
33 \\
39 \\
43\end{array}$ & $\begin{array}{l}38 \\
24 \\
48 \\
9 \\
24 \\
36\end{array}$ & $\begin{array}{l}\text { UL } \\
\text { RUL, LL } \\
\text { UL } \\
\text { 4L } \\
\text { RUL } \\
\text { UL }\end{array}$ & $\begin{array}{l}+ \\
+ \\
+ \\
+ \\
+ \\
+\end{array}$ & $\begin{array}{l}0 \\
+ \\
0 \\
+ \\
+ \\
+\end{array}$ & $\begin{array}{l}\text { N } \\
0 \\
D \\
N \\
D \\
D\end{array}$ & $\begin{array}{r}0 \\
320 \\
320 \\
80 \\
320 \\
320\end{array}$ & $\begin{array}{l}0.45 \\
0.22 \\
0.63 \\
0.33 \\
0.87 \\
0.49\end{array}$ & \\
\hline F18 & 40 & 48 & UL, RLL & + & 0 & 0 & 160 & ND & \\
\hline
\end{tabular}

$\mathrm{LL}=$ Lower limb; UL = upper limb; $\mathrm{R}=$ right; $\mathrm{L}=$ left $\mathrm{M}=$ male; $\mathrm{F}=$ female; $\mathrm{DTR}=$ deep tendon reflexes; $0=$ abolished; $\mathrm{N}=$ normal; $\mathrm{D}=$ diminshed; ND = not done; CTX = cyclophosphamide; IVIg = intravenous immunoglobulins

The treatment response with IVIg and cyclophosphamide is expressed in the last column as percentage of the initial strength score. 
increase in strength had high titres of $\operatorname{IgM}$ antiGM1 antibodies, without significant changes in IgG concentrations. Of the six patients who did not improve with IVIg, five had no IgM antiGM1 antibodies and one had only a slight increase (40, table). During the study, antiGM1 antibody titres measured in serum before each course of IVIg did not significantly change. A reduction of anti-GM1 titres was found in two patients after starting cyclophosphamide (patients 11 and 17), despite the absence of clinical improvement in the first case.

\section{Discussion}

Several previous studies have shown the beneficial effect of IVIg in patients with multifocal motor neuropathy over a period of less than 12 months; for example, IVIg was found to be effective in 52 of 60 treated patients $(87 \%) .^{8-18}$ Our study was designed to assess its efficiency on a large number patients over longer periods. Twelve patients $(67 \%)$ showed an increase in strength $>30 \%$ at the end of the study, with a mean follow up of 25.3 months, the longest period of evaluation being four years. It was possible to differentiate two types of response after the first treatment: in the first group, eight patients improved temporarily and it was necessary to treat them by periodic infusions at intervals based on the findings at the first treatment with a mean interval of 53 days. The other group of four patients improved after the first infusion and continued to improve with intermittent IVIg treatment for several months, allowing treatment to be withdrawn for two of them when recovery was complete, without deterioration after one year. Previous cases of long term remissions are very rare ${ }^{81011}$ but justify careful evaluation of treatment by repetitive examinations after the first course of IVIg on the one hand, and by trying to reduce the frequency of infusions leading possibly to a withdrawal of IVIg on the other.

Improvement was obtained after the first course of IVIg, suggesting that it is necessary to rapidly try other immunosuppressive drugs in patients who fail to improve after the second course of IVIg.

Elliott and Pestronk ${ }^{19}$ documented a patient who deteriorated with monthly IVIg infusions for seven months after an initial improvement. This type of evolution seems to be rare. In our study, only one patient (3) out of 12 who initially improved after IVIg further deteriorated. Moreover, the maintenance of the beneficial effect of IVIg long term was documented in two patients over four years.

The long term tolerance to IVIg was confirmed although minor reactions were common. We did not find any transmission of HIV or $\mathrm{HCV}$ in our patients, who received large quantities of IVIg over a long period. However, the monitoring of serum aminotransferases and HCV antibodies at least twice a year is recommended. ${ }^{20}$

When patients do not benefit from IVIg infusions, cyclophosphamide is an alternative as Feldman et $\mathrm{al}^{7}$ reported a progressive improvement in all patients they treated. We have treated only three patients with intravenous cyclophosphamide and two with oral therapy. Only one patient improved with cyclophosphamide after failure of IVIg treatment, but the dose was lower than those used by Feldman et al. ${ }^{7}$ Hence, if a consensus is realised about the choice of IVIg as a first line treatment, the indication of intravenous cyclophosphamide if IVIg is not effective has yet to be proved by a controlled trial on larger groups of patients. Another indication for cyclophosphamide was proposed by NobileOrazio et $a l^{11}$ who reduced the frequency of IVIg infusions by the addition of low doses (1-2 $\mathrm{mg} / \mathrm{kg} /$ day) of the cytotoxic agent in two patients. We obtained the same result in one of two patients.

As in most studies, ${ }^{11-13}$ it was not possible to document significant changes of anti-GM1 concentrations on long term IVIg therapy, although this was obtained with cyclophosphamide in two patients, who nevertheless did not clinically improve. However, a correlation between the initial presence of high titres of IgM anti-GM1 antibodies without IgG and the long lasting response to IVIg was present. This correlation has not been reported by others, ${ }^{18}$ and further studies are needed to confirm the clinical value of IgG and IgM anti GM1 determination as a factor predictive of response to IVIg.

1 Lewis RA, Sumner AJ, Brown MJ, Asbury AK. Multifocal demyelinating neuropathy with persistent conduction block. Neurology 1982;32:958-64.

2 Chad DA, Hammer K, Sargent J. Slow resolution of multifocal weakness and fasciculation: a reversible motor neuron syndrome. Neurology 1986;36:1260-3.

3 Parry GH, Clarke S. Multifocal acquired demyelinating neuropathy masquerading as motor neuron disease. Muscle Nerve 1986;11:103-7.

4 Freddo L, Yu RK, Latov N et al. Gangliosides GM1 and GDlb are antigens for IgM M-protein in a patient with motor neuron disease. Neurology 1986;36:454-8.

5 Shy ME, Heiman-Patterson T, Parry GJ, Tahmoush A, Evans A, Schick PK. Lower motor neuron disease in a patient with autoantibodies against $\mathrm{Gal}(\beta 1-3) \mathrm{Gal} \mathrm{Nac}$ in gangliosides GM1 and GD1b: improvement following immunotherapy. Neurology 1990;40:842-4.

6 Pestronk A, Cornblath DR, Ilyas AA, et al. A treatable multifocal motor neuropathy with antibodies to GM1 ganglioside. Ann Neurol 1988;24:73-8.

7 Feldman EL, Bromberg MB, Albers JW, Pestronk A. Immunosuppressive treatment in multifocal motor neuropathy. Ann Neurol 1991;30:397-401.

8 Kaji R, Shibasaki H, Kimura J. Multifocal demyelinating motor neuropathy: cranial nerve involvement and motor neuropathy: cranial nerve involvement

9 Charles N, Vial C, Moreau T, Benoit P, Bierme T, Bady B. Intravenous immunoglobulin treatment in multifocal motor neuropathy. Lancet 1992;340:182.

10 Kermode AG, Laing BA, Carroll WM, Masta-glia FL. Intravenous immunoglobulin for multifocal motor neuropathy. Lancet 1992;340:920-1.

11 Nobile-Orazio E, Meucci N, Barbieri S, Carpo M, Scarlato G. High-dose intravenous immunoglobulin therapy in multifocal motor neuropathy. Neurology 1993;43:537-44.

12 Chaudhry V, Corse AM, Cornblath DR. Multifocal motor neuropathy: response to human immune globulin. Neurology 1993;33:237-42.

13 Azulay J.Ph, Blin $\mathrm{O}$, Pouget $\mathrm{J}$, et al. Intravenous immunoglobulin treatment in patients with motor neuron syndromes associated with anti-GMl-antibodies: a double-blind, placebo-controlled study. Neurology 1994; 44:429-32.

14 Dalakas MC, Stein DP, Otero C, Szekul E, Cupler EJ, McCrosky S. Effect of high-dose intravenous immunoglobulin on amyotrophic lateral sclerosis and multifocal globulin on amyotrophic lateral sclerosis and

15 Donaghy M, Mills KR, Boniface SJ, et al. Pure motor demyelinating neuropathy: deterioration after steroid treatment and improvement with intravenous immunoglobulin. F Neurol Neurosurg Psychiatry 1994;57:778-83.

16 Leger JM, Ben Younes-Chennoufi A, Chassande B, et al. Human immunoglobulin treatment of multifocal motor neuropathy and polyneuropathy associated with mono- 
clonal gammopathy. 7 Neurol Neurosurg Psychiatry 1994; 57(suppl):46-9.

17 Van den Berg LH, Kerkhoff H, Oey PL, et al. Treatment of multifocal motor neuropathy with high dose intravenous immunoglobulins: a double-blind placebo controll study. F Neurol Neurosurg Psychiatry 1995;59:248-52.

18 Bouche P, Moulonguet A, Ben Younes-Chennoufi, et al. Multifocal motor neuropathy with conduction block: a study of 24 patients. $\mathcal{F}$ Neurol Neurosurg Psychiatry 1995; 59:38-44.

19 Elliot JL, Pestronk A. Progression of multifocal motor neuropathy during apparently successful treatment with human immunoglobulin. Neurology 1994;44:967-8.

20 Schiff RL. Transmission of viral infections through intravenous immune globulin. $N$ Engl $f$ Med 1994;331: 1649-50.

\section{HISTORICAL NOTES}

\section{Wepfer's description of the apoplexy of Malpighi}

Wepfer showed that apoplexy is due to cerebral haemorrhage. In Historiae apoplecticorum, published in $1658,{ }^{1}$ is a detailed description of four cases, his first having been studied in 1655 . The account of one such case and a brief history of Wepfer is reproduced elsewhere. ${ }^{2}$ This classic text also contains a section: The history of the sickness of Marcello Malpighi, the Pope's physician; with an account of the dissection of his corps.

Malpighi (1628-94) was professor of anatomy at Bologna, Pisa, and Messina. His work formed the basis for the studies of histology, providing accurate descriptions of the lungs, kidneys, spleen, skin, and liver. $\mathrm{He}$ first described the capillaries and the layer of the skin and demonstrated the lymphatic follicles in the spleen, both of which bear his name. Much of modern embryology can be said to be grounded in his examinations of the chick embryo. Biologists owe Malpighi a debt for his early studies on the anatomy of the silkworm.

$\mathrm{He}$ achieved considerable eminence and repute, and was appointed physician to Pope Innocent XII.

Wepfer relates the distinguished anatomist's past history of palpitations, stones in the kidneys and bladder, and gout.

On "July 25 th 1694 at which Time he was seized in the 66th year of his Age, about 1 a clock in the Afternoon, with an Apoplexy ... attended with a Palsie of the whole right Side, and a distortion of the mouth and Right Eye".

Wepfer describes his treatments with blood letting and cupping.

"After struggling 40 Days with a long Train of grievous Symptoms, particularly a Light-Headedness, a Capiplenium, ${ }^{\star}$ and other Accidents, he got clear of the Apoplexy, and Palsie ... but suffer'd much by the foregoing Disease in his Memory and Reason, and melted into tears upon the slightest Occasion.

He was seiz'd Nov, 29 with a fresh fit of an Apoplexy after the Injection of a customary Glyster in the morning. This

*This word is not to be found in the OED; I presume it is derived from $L$ caput (head) and plenium (a fullness), hence derived from $L$ new fit was usher'd in by a grievous Vertigo, with a fit of a Stone in the Bladder for eight Days . . . he dy'd four Hours after the Invasion."

The dissection of the corps showed enlargement of the heart and

"left Ventricle as thick as the Breadth of two Fingers. The left Kidney was in a natural State but the right was half as big again as the left, and the Bason of it was so much dilated that one might easily thrust 2 Fingers into it... In the Bladder we found a little Stone .

When I opened his Head I found in the Cavity of the right Ventricle of the Brain an Extravasation of about two pints of black clotted Blood, which was the cause of his Apoplexy and Death. In the left Ventricle we found about an Ounce and a half of yellowish Water, with a small Quantity of little Grains of Sand mix'd with it. The Blood Vessels of the Brain were dilated and broke on all Hands. The whole Compass of the dura Mater adhered tenaciously and praeternaturally to the Cranium. And this is the Sum of what I observ'd in Dissecting his Corps, Dec 7, 1694."

This history is remarkable for showing the several predisposing factors for cerebral haemorrhage, though the absence of a means of measuring blood pressure precludes any certainty that he was hypertensive. The two stage illness is clear with a right hemiplegia accompanied by a small yellow watery collection, probably of putaminal origin in July, and the second attack, some four months later, a massive right sided haemorrhage that took his life within four hours. Whether or not the grains of sand were haemosiderin laden granulations of the choroid or ependyma of the left ventricle, we are left to guess.

\section{JMS PEARCE 304 Beverley Road, \\ East Yorks HU10 $7 B$ Anlaby,}

1 Wepfer JJ. Historiae apoplecticorum. 1658. English translation from Bagvili's Practice of Physik, London 1704: cited in Major RH. Classic descriptions of disease, 3rd ed. cited in Major RH. Classic descriptions of dis: Charles C Thomas, 1945:474-7.

2 Pearce JMS. Johann Jakob Wepfer (1620-95) and cerebral haemorrhage. $\exists$ Neurol Neurosurg Psychiatry 1997;62: 389 . 